\title{
Analysis of WRF Model Performance over Subtropical Region of Delhi, India
}

\author{
Manju Mohan and Shweta Bhati \\ Centre for Atmospheric Sciences, Indian Institute of Technology Delhi, Hauz Khas, New Delhi 110 016, India \\ Correspondence should be addressed to Manju Mohan, mmohan6@hotmail.com
}

Received 22 December 2010; Revised 4 March 2011; Accepted 29 March 2011

Academic Editor: Sven-Erik Gryning

Copyright ( $) 2011$ M. Mohan and S. Bhati. This is an open access article distributed under the Creative Commons Attribution License, which permits unrestricted use, distribution, and reproduction in any medium, provided the original work is properly cited.

\begin{abstract}
Model performance and sensitivity to model physics options are studied with the Weather Research and Forecasting model (version 3.1.1) over Delhi region in India for surface and upper air meteorological parameters in summer and winter seasons. A case study with the model has been performed with different configurations, and the best physics options suited for this region have been, determined. Comparison between estimated and observed data was carried out through standard statistical measures. Generally, the combination of Pleim-Xiu land surface model, Pleim surface layer scheme, and Asymmetric Convective Model has been found to produce better estimates of temperature and relative humidity for Delhi region. Wind speed and direction estimations were observed best for MM5 similarity surface layer along with Yonsei University boundary layer scheme. Nested domains with higher resolutions were not helpful in improving the simulation results as per the current availability of the data. Overall, the present case study shows that the model has performed reasonably well over the subtropical region of Delhi.
\end{abstract}

\section{Introduction}

Numerical weather prediction models have different sets of physical parameterization configuration options. As the model becomes more sophisticated, greater number of physical processes can be incorporated into it, and there is a range of physical schemes which can be used to simulate them. Thus, one of the essential steps in numerical weather simulation is to choose the best set of physics options for the region and time period under consideration. Numerous sensitivity studies for one or more physics options of WRF model have been undertaken in different parts of the world such as Spain [1], Japan and Korea [2], Alaska [3], South America [4], western United States [5], southern United States [6], West Africa [7], and others. In India, some sensitivity studies for WRF have been undertaken which mainly focus on extreme events like thunderstorm [8], tropical cyclone [9], and heavy precipitation [10-12]. The present work is a case study in which an attempt is made to apply several physics options of the Weather Research and Forecasting model (WRF v 3.1.1) to a subtropical region, namely, Delhi in India, for examining model sensitivity and evaluating the model's performance as suited to this region.

\section{Model and Configurations}

2.1. WRF Modeling System. The Weather Research and Forecasting model is developed for mesoscale modeling and is a supported "community model", that is, a free and shared resource with distributed development and centralized support. Its development is led by NCAR, NOAA/ESRL, and NOAA/NCEP/EMC with partnerships and collaborations with universities and other government agencies in the US and overseas. The Advanced Research WRF (ARW) dynamical core has an equation set which is fully compressible, Eulerian and nonhydrostatic with a run-time hydrostatic option [13]. It is conservative for scalar variables. The model uses terrain-following, hydrostatic-pressure vertical coordinate with the top of the model being a constant pressure surface. The horizontal grid is the Arakawa- $\mathrm{C}$ grid. The time integration scheme in the model uses the thirdorder Runge-Kutta scheme, and the spatial discretization employs 2nd- to 6th-order schemes. The model supports both idealized and real-data applications with various lateral boundary condition options. The model also supports oneway, two-way, and moving nest options [14]. 
2.2. Model Configurations. There are various options for physical parameterisations of key boundary layer phenomena in this model for (i) microphysics, (ii) cumulus parameterization (CP), (iii) surface layer (SL), (iv) landsurface model (LSM), and (v) planetary boundary layer (PBL). The present study captures all of the above physical parameterisations in various options representing all of these five categories. The model experiments based on these are detailed in Table 1. The following subsections describe the physical parameterisations in each of these categories [15] and their consideration for model simulations in this study.

2.2.1. Microphysics. Microphysics includes explicitly resolved water vapor, cloud, and precipitation processes. Out of the several microphysics schemes of the model, the options suitable for high resolution-domain are chosen as the innermost domain is of a resolution of $2 \mathrm{~km}$. These include Purdue Lin scheme [16] and WRF Single-Moment 6-class scheme (WSM6) [17]. However, a relatively simpler Eta microphysics option [18] has also been chosen for comparison.

2.2.2. Cumulus Parameterization. Cumulus parameterization schemes are responsible for the subgrid-scale effects of convective and/or shallow clouds but are valid only for coarse-grid sizes such as greater than $10 \mathrm{~km}$. Grell 3d ensemble cumulus scheme is most suitable for the present analysis as it is applicable for higher-resolution domains allowing for subsidence in neighboring columns. Apart from this, Kain-Fritsch scheme [19] is also considered for model experiments since this is the most widely exercised option for Cumulus parameterization.

2.2.3. Surface Layer and Planetary Boundary Layer. The surface layer schemes calculate friction velocities and exchange coefficients that enable the calculation of surface heat and moisture fluxes by the land-surface models and surface stress in the planetary boundary layer (PBL) scheme. The PBL schemes determine the flux profiles within the wellmixed boundary layer and the stable layer, and thus provide atmospheric tendencies of temperature, moisture (including clouds), and horizontal momentum in the entire atmospheric column. In some cases, a surface layer option is tied to a particular boundary layer option. In the present study, all surface layer schemes applicable in WRF, that is, MM5 similarity [20], Eta similarity [21], Pleim-Xiu surface layer [22], and QNSE surface layer schemes have been used. The default boundary layer scheme was MellorYamada-Janjic scheme [21] while the other options that were tried were Yonsei University scheme [23] (tied with MM5 similarity for surface layer), asymmetric convective model (ACM2) scheme (tied with Pleim-Xiu surface layer) [22], and quasinormal scale elimination (QNSE) PBL. Other PBL schemes such as BouLaC PBL and LES PBL are applicable to their relevant special cases and thus have not been tested in the present study.

2.2.4. Land Surface Model (LSM). Land surface models (LSMs) play an important role in building soil temperature and moisture profiles and canopy properties. Consequently, the land surface schemes work as a fuel for atmospheric processes or in other words provide the forcing from the ground below to the lower part of the boundary layer which subsequently gets transported to the rest of the atmosphere. LSMs use atmospheric information from the surface layer scheme, radiative forcing from the radiation scheme, and precipitation forcing from the microphysics and convective schemes, together with internal information on the land's state variables and land-surface properties, to provide heat and moisture fluxes over land points and sea-ice points.

These fluxes provide a lower boundary condition for the vertical transport to the PBL. Out of all the LSMs applicable in WRF, Noah Land Surface Model (default), RUC Land Surface Model, and Pleim-Xiu Land Surface Model have been applied in the simulations. The simple 5-layer thermal diffusion scheme has not been tested as it includes only soil temperature. Also, since the area under analysis is a subtropical region, fractional sea-ice scheme (which requires snow cover data) has not been considered.

In the present study, a total of nine simulations for each season were carried out. A default set of schemes was fixed for one simulation which was named as Case 1. On the basis of the more widely used options, the default case was fixed as Purdue Lin Scheme [16] for Microphysics, KainFritsch scheme [19] for Cumulus parameterization, and Eta Similarity theory [21] for Surface Layer, Noah Land Surface Model [24, 25], and Mellor-Yamada-Janjic Planetary Boundary Layer. Thereafter, different options were adopted for a given physics category keeping options in other physics categories as constant. Table 1 lists out the various options that were used in the simulations. In all, apart from the configuration in default case simulation (simulation no. 1), two simulations for microphysics variations (simulation no. 6,8 ), three simulations for surface layer schemes (simulation no. $2,4,7$ ), two simulations for LSMs variations (simulation no. 3,7 ), three simulations for surface layer schemes (simulation no. 2, 4, 7), three simulations for PBL schemes (Simulation no. 4, 5, 7), and one simulation for cumulus parameterization (simulation no. 9) have been tested. Rapid radiative transfer model (RRTM) longwave radiation scheme [26] and Dudhia [27] shortwave radiation scheme have been applied to all simulations.

\section{Model Domain and Simulation Period}

Figure 1 shows the domains used for modeling in the present study. The parent domain (D1) covers the Indian subcontinent with a spatial resolution of $18 \mathrm{~km}$. The domain is a peninsular region flanked by Himalayan mountains in the north. The first nested domain (D2) constitutes northern India region with resolution of $6 \mathrm{~km}$. The second nested domain (D3), which is the area under analysis, covers the city of National Capital Region of Delhi and surroundings with a domain resolution of $2 \mathrm{~km}$ centered at $28.52^{\circ} \mathrm{N}$ and $77.12^{\circ} \mathrm{E}$. D3 lies in the subtropical climate zone (Keppen classification: Cwa). Geologically, this region is bounded by the Indo-Gangetic alluvial plains in the North and East, by 


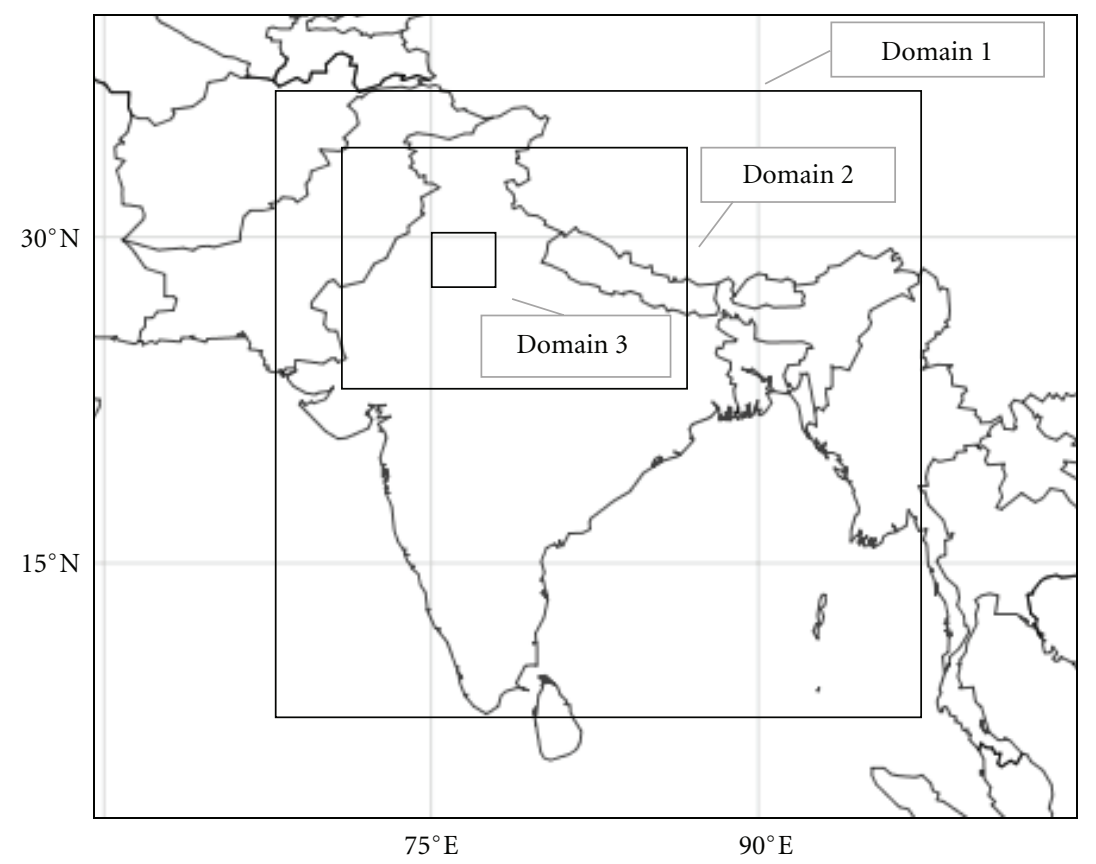

Figure 1: Model domains.

Thar Desert in the West and by old Aravalli hill ranges in the South. There is a ridge trending along NNE-SSW direction which constitutes a small area of Delhi's terrain which is otherwise generally flat [28]. Seasonally, the year can be divided into four main periods. Summer is experienced in the months of March-June followed by monsoon months of July, August, and September. Postmonsoon months are October and November while the period of DecemberFebruary constitutes the winter season. The maximum temperature ranges from 41 to $45^{\circ} \mathrm{C}$ in peak summer season and the minimum temperature in winter season is in the range of $3-6^{\circ} \mathrm{C}$ in coldest period of Dec.-Jan. For the present study, summer and winter conditions have been simulated for about two weeks in each season. The period from 29 April 2009 00:00 UTC to 14 May 2009 00:00 UTC was chosen for summer simulations while for the winter season the simulation period was from 25 December 2009 00:00 UTC to 9 January 2010 00:00 UTC. The chosen simulation periods are representative of peak periods of their respective seasons with no recorded case of precipitation. The first day of each simulation was considered as spin-up period, and the remaining 14 days have been analysed. The vertical resolution of the model is 33 levels with pressure ranging from $976 \mathrm{mbar}$ to $54 \mathrm{mbar}$. Up to a height of $2.2 \mathrm{~km}$, there are 10 levels spaced at approximately $0.24,0.320 .42,0.55$, $0.7,0.91,1.16,1.49,1.87$, and $2.26 \mathrm{~km}$.

\section{Data and Analysis}

USGS 24 classification category land-use data was used for interpolating topography and land use with spatial resolution of $30^{\prime \prime}$. NCEP final analysis data (FNL) of resolution $1^{\circ}$ was used as input for initial and boundary conditions to the model. The sources of these datasets are available for download from WRF model website (http://www.mmm.ucar.edu/wrf/users/downloads.html).

The output has been generated from the model at every 30 minutes. The data used for validation of surface variables has been derived from http://www.wunderground.com/. This website collects weather conditions directly from weather stations located in various countries which are owned by government agencies and international airports [29]. In Delhi, there are two aeronautical weather stations of Indian Meteorological Department which are part of WMO World Weather Information Service. First is the aeronautical weather station located at Indira Gandhi International Airport in Delhi $\left(28.57^{\circ} \mathrm{N}, 77.12^{\circ} \mathrm{E}\right)$ which will be referred to as "station 1" hereafter in this text. Within Delhi region, this is the only location for which data is available in public domain at an interval of 30-60 minutes. The other weather station is at Safdarjung Airport $\left(28.58^{\circ} \mathrm{N} 77.2^{\circ} \mathrm{E}\right)$ and surface data for this site is available at 3 hour interval. This station will be referred to as "station 2" hereafter in this text. The observations are taken using standards techniques and practices as laid out by WMO [30]. Statistical measures such as correlation score $(r)$, root mean squared error (RMSE), fractional bias $(\mathrm{FB})$, and number of estimated values within a factor of $2\left(\mathrm{FAC}_{2}\right)[31,32]$ have been used for evaluation of model performance. Values of these measures were estimated for all key meteorological variables at the surface, namely, temperature, wind speed, and relative humidity for each simulation.

Station 2 is also the source of radiosonde measurements which has been used for analysis of upper air variables such as temperature and wind speed. Upper air data is available for two soundings per day. The observed upper air data has 


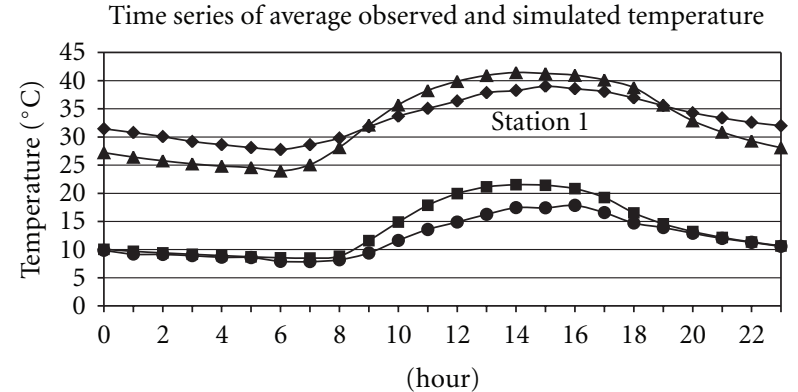

(a)

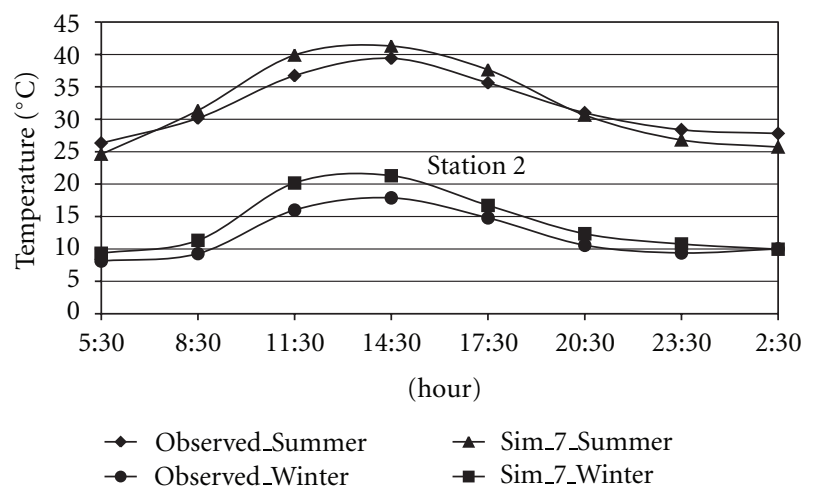

(b)

Figure 2: Comparison of average observed and simulated (simulation 7) surface temperature for station 1 and station 2.

been accessed from Integrated Global Radiosonde Archive of National Climatic Data Centre [33].

\section{Results and Discussions}

\subsection{Surface Variables}

5.1.1. Temperature and Relative Humidity. Statistical evaluation for both stations 1 and 2 is presented in Tables 2, 3, 4, and 5 where the best values obtained for each case are written in bold. It can be noted that simulation 7 works satisfactorily for temperature in terms of statistical evaluation reporting least RMSEs and fractional bias and highest correlations with observed data for temperature. Figure 2 displays diurnal variation of observed and estimated surface temperature by simulation 7 averaged over each hour for the entire study period comprising 14 days each of both summer and winter seasons for both the observation points. Top panel shows hourly variation at station 1 and bottom panel displays 3-hourly variation for station 2. By and large, there is a general tendency towards overprediction of daytime temperature averages while underprediction for night-time temperatures during summer period. However, a consistent overprediction is shown for the winter period; however night-time prediction is far closer to observations than the daytime predictions. Different studies in past have observed both underprediction $[6,34]$ and overestimation $[7,35]$ for temperature, but the result of present study is closest to the one noted by Hanna et al. [36] which was carried out in Oklahoma and Kansas (US) that observed underestimation during night-time and overestimation in daytime. In India, Das et al. [37] observed underprediction for temperature during monsoon season.

Simulation 7 is an experimental case with Pleim-Xiu (PX) land surface model, Pleim surface layer scheme, and Asymmetric Convective Model for PBL. The PX LSM coupled with the ACM2 PBL and Pleim surface layer scheme has been found to be well suited for extended simulations (i.e., more than a week such as in present study) where the indirect soil moisture and temperature nudging scheme leads to more accurate near-surface meteorology [22].

Overall, relative humidity is underpredicted by all simulations in the model as indicated by positive fractional bias in Tables 2-5. As with temperature, for relative humidity also, some studies have observed overestimation such as in Mediterranean regions [1] while some others have observed underprediction such as in dry western Africa [7].

For relative humidity also, simulation 7 is the bestperforming simulation for both summer and winter seasons with consistently least RMSE and FB and highest $r$ and $\mathrm{FAC}_{2}$. The PX LSM simulates the evolution of soil moisture and temperature in two layers $(0-1$ and $1-100 \mathrm{~cm})$; canopy moisture consists of algorithms for nudging of soil moisture and soil temperature. The algorithms of the coupled ACM2 PBL allow for smooth transition from eddy diffusion in stable conditions to the combined local and nonlocal transport in unstable conditions. This makes this combination well suited for consistent transport of moisture fluxes within the PBL.

From the above discussions, it may be concluded that simulation 7 performs best for both temperature and relative humidity.

5.1.2. Wind Speed and Direction. Wind direction can be better represented through wind rose diagram as all directions together with wind speed can be clearly displayed. Wind roses have been constructed for summer and winter simulation period in Figures 3 and 4 for station 1. Since hourly data is not available for station 2, it has not been included for wind rose analysis. However, statistical analysis of wind speed has been performed for estimations at both stations 1 and 2 in Tables 2-5. A general tendency by the model to overpredict wind speed is observed by all simulations which has also been observed in many earlier studies $[1,2,4,36]$. As noted in earlier studies, wind speed is significantly affected by local fluctuations especially in highly unstable conditions such as in summer [6], and thus wind sensitivities tend to have more "noise" [38]. Nonetheless, for present study, simulation 4 clearly shows the best performance amongst all the 9 cases for both summer and winter conditions at both stations. Major difference between default case and simulation 4 lies in the two PBL schemes used, that is, the local and nonlocal approach, respectively. The YSU scheme (used in simulation 4) takes into account momentum and mass transfer from large-scale eddies, whereas the MYJ scheme (in default case simulation) determines diffusion and turbulence locally [7, 39]. 

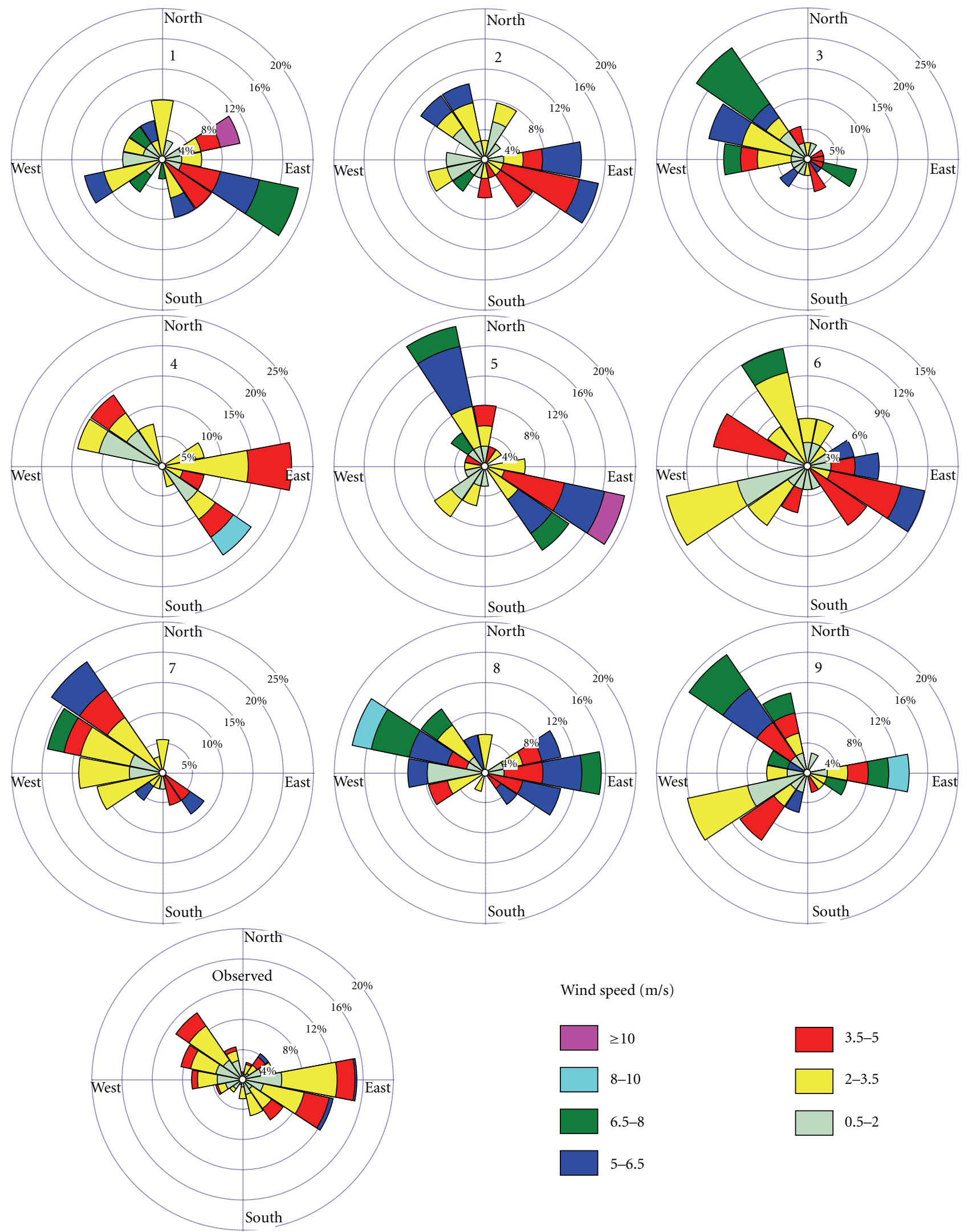

Wind speed $(\mathrm{m} / \mathrm{s})$

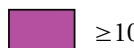

$3.5-5$

$\square-10$

$2-3.5$

$\square .5-8$

$0.5-2$

$5-6.5$

FIgURE 3: Wind roses for station 1 for summer simulations. 

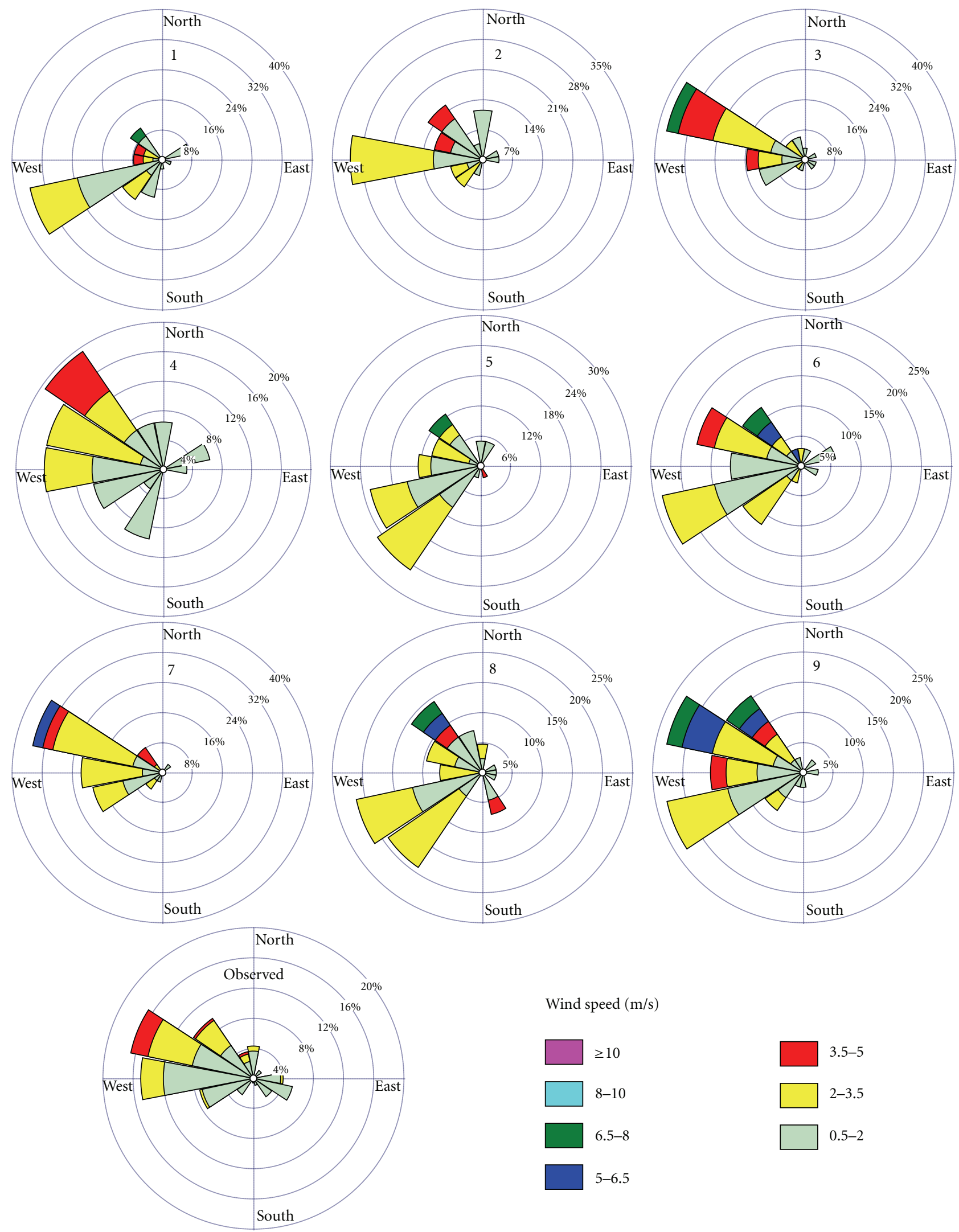

Wind speed $(\mathrm{m} / \mathrm{s})$

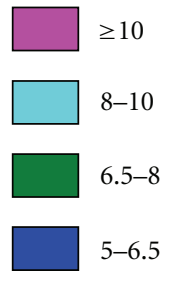

$3.5-5$

$2-3.5$

$0.5-2$

FIGURE 4: Wind roses for station 1 for winter simulations. 


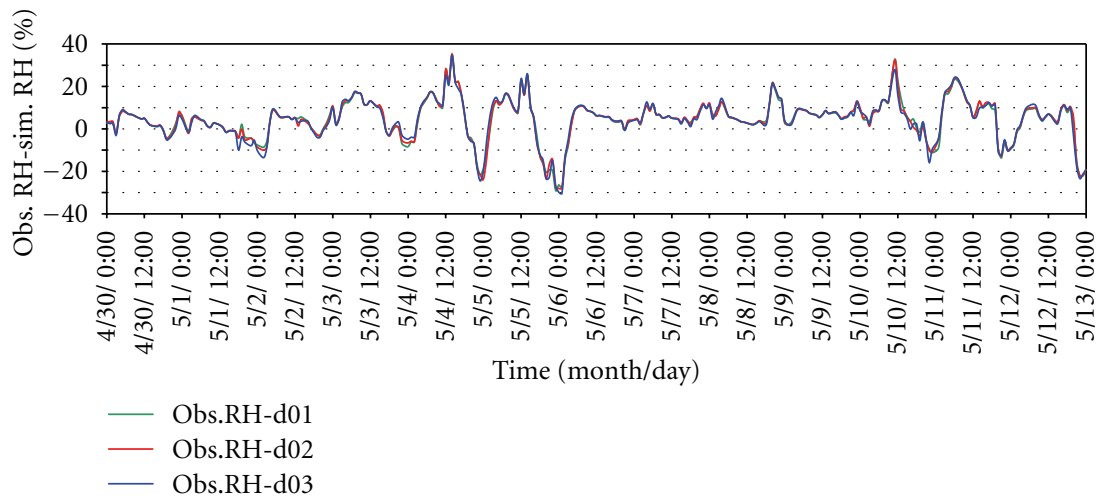

(a)

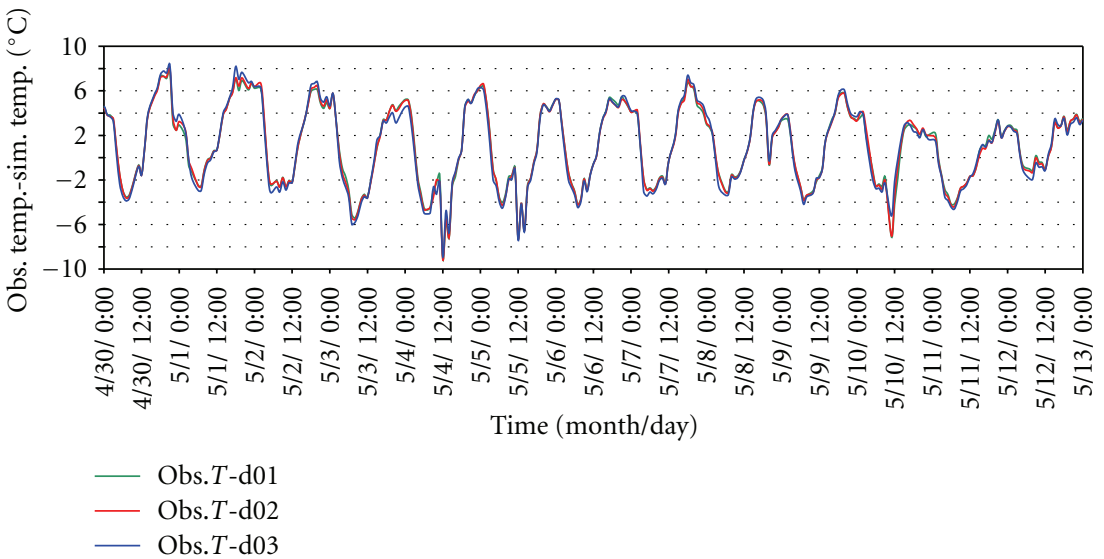

(b)

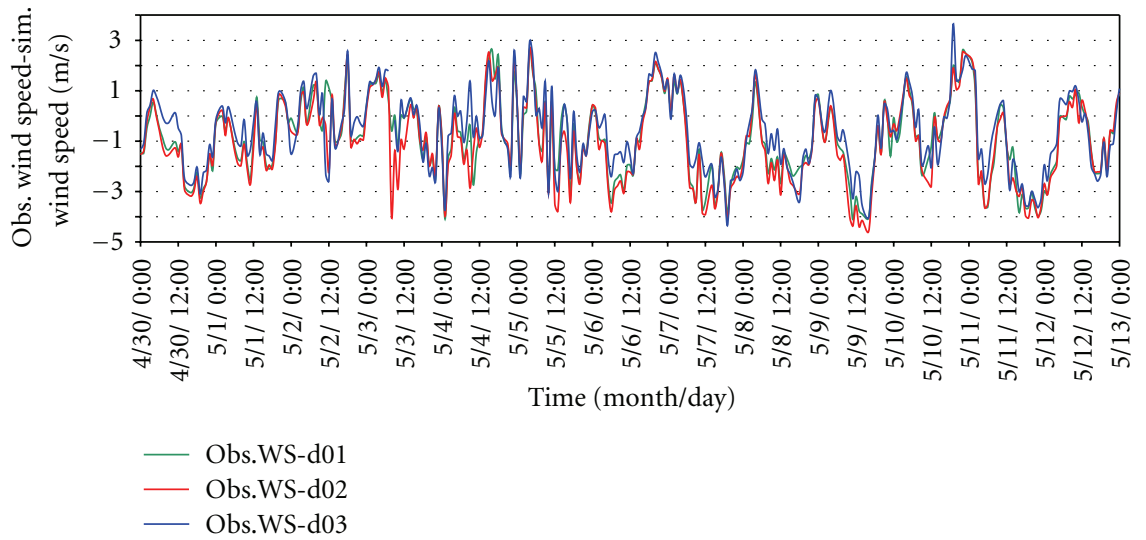

(c)

Figure 5: Comparison of difference between observed and estimated (at different domain resolutions) temperature, wind speed and direction, and relative humidity for station 1 .

Wind direction, being an angular quantity, has not been analysed statistically because statistical measures are based on arithmetic difference between observed and estimated quantities which is not applicable for vector parameters like wind direction. From wind roses, however, it can be noted that simulation 4 is the closest to observed pattern in terms of both direction and speed for summer and winter season (Figures 4 and 5).
5.2. Impact of Domain Resolution. WRF is suitable for use across scales ranging from meters to thousands of kilometers (http://www.mmm.ucar.edu/wrf/users/). Simulations over higher-resolution domains are computationally expensive. Thus, comparison of simulations at different domain resolutions was undertaken in the present study. Figures 5 and 6 display time series of the difference between observed values and best-performing simulations for each variable, that is, temperature (simulation 7), wind speed (simulation 


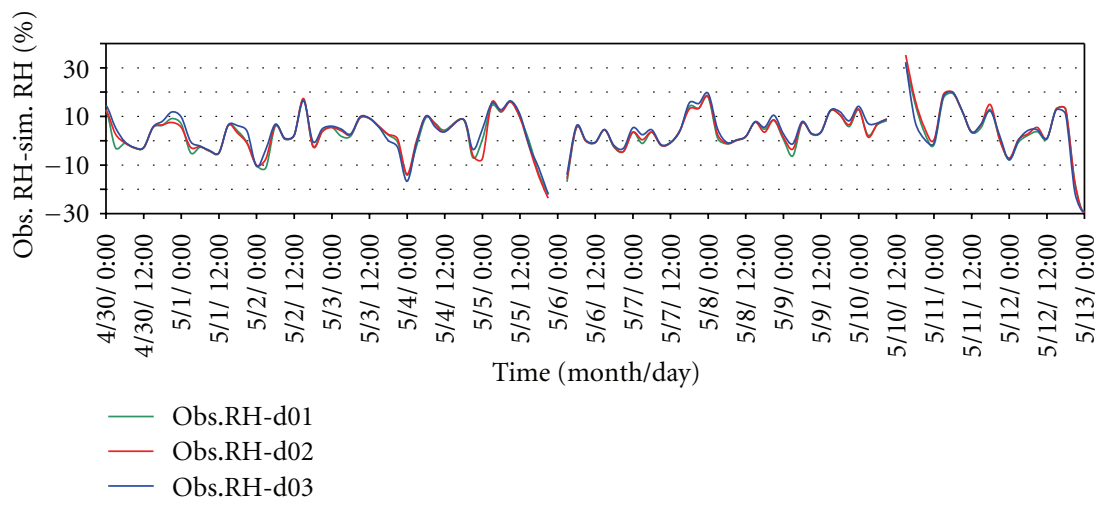

(a)

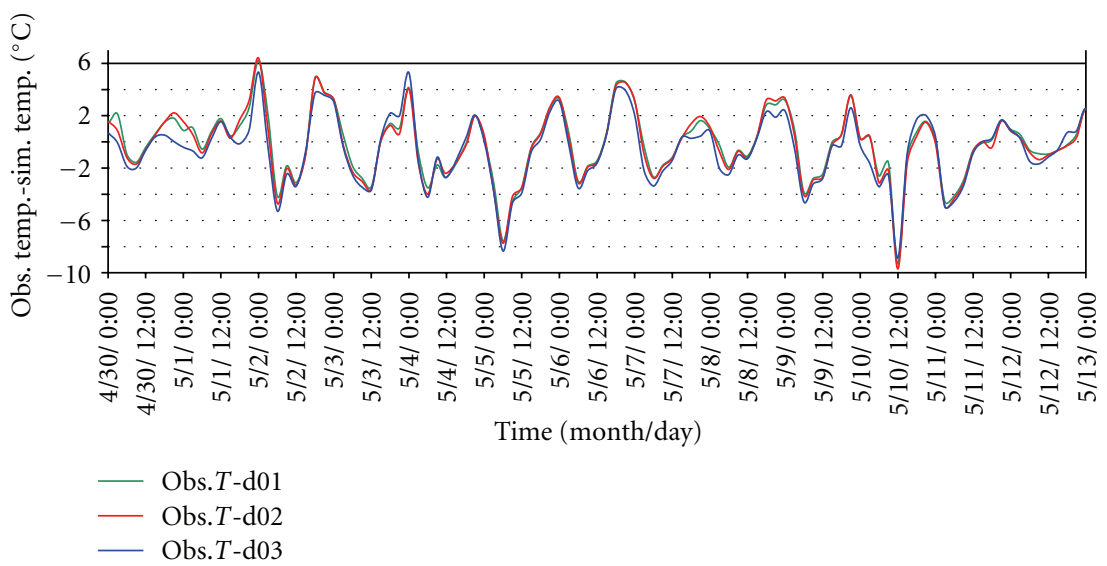

(b)

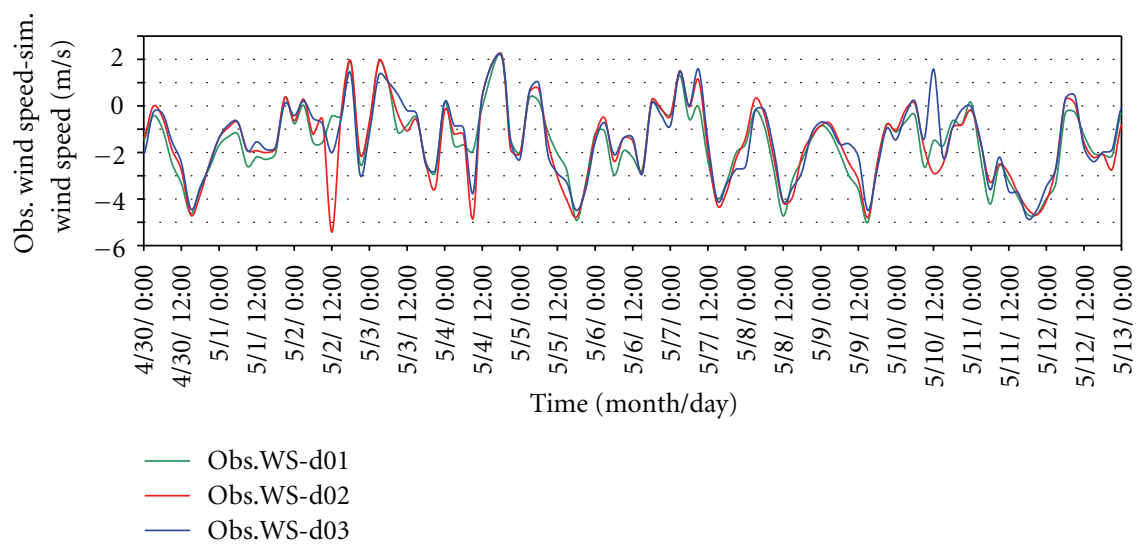

(c)

FIGURE 6: Comparison of difference between observed and estimated (at different domain resolutions) temperature, wind speed and direction, and relative humidity for station 2 .

4), and relative humidity (simulation 7 ) at different domain resolutions (d01: $18 \mathrm{~km}, \mathrm{~d} 02: 6 \mathrm{~km}, \mathrm{~d} 03: 2 \mathrm{~km}$ ) for summer season at station 1 and 2, respectively. From the time series plots, it is clear that a resolution of $2 \mathrm{~km}$ does not significantly improve the simulation results when compared with 18 and $6 \mathrm{~km}$ resolution cases. At $18 \mathrm{~km}$ resolution, the linear distance between observation station point and model grid point was about $932 \mathrm{~m}$ while at $2 \mathrm{~km}$ resolution, this distance was $117 \mathrm{~m}$. The difference between observed and simulated values at these stations is quite similar even when the output is obtained at $18 \mathrm{~km}$ resolution or $6 \mathrm{~km}$ resolution. Similar results were obtained for winter period also, though the plots are not shown here. Higher resolutions are needed for certain studies like local ambient temperature or air quality studies, and improved model inputs should be provided for such cases. Improved model simulations at higher resolutions may perhaps require better model inputs at finer resolutions such as meteorological parameters, landuse data, and assimilation with more local data sources. 


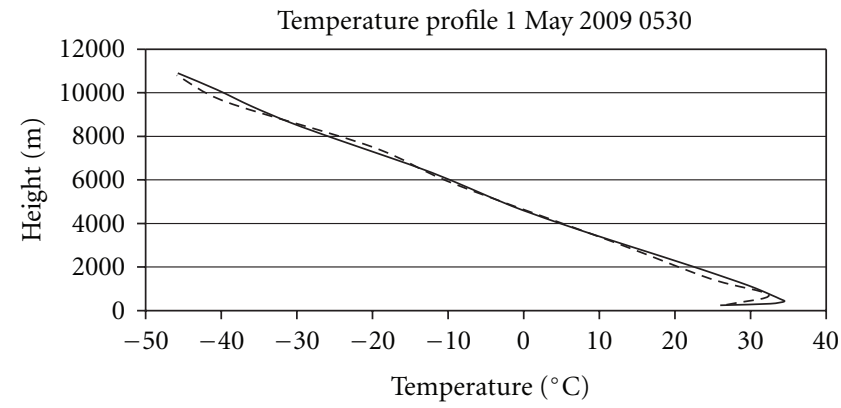

(a)

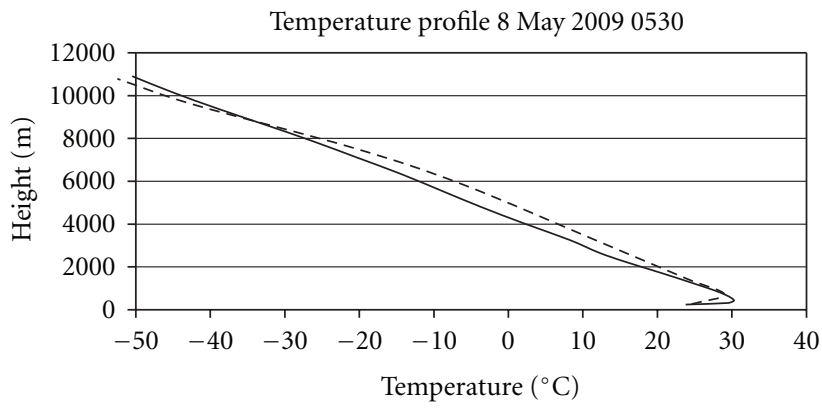

- Simulated

- - - Observed

(c)

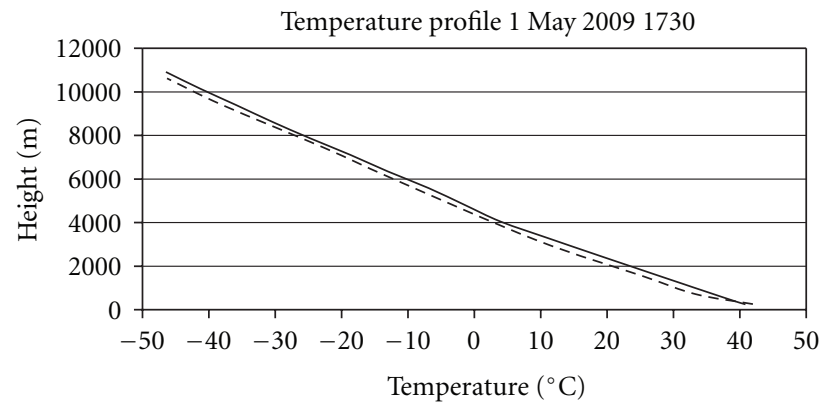

(b)

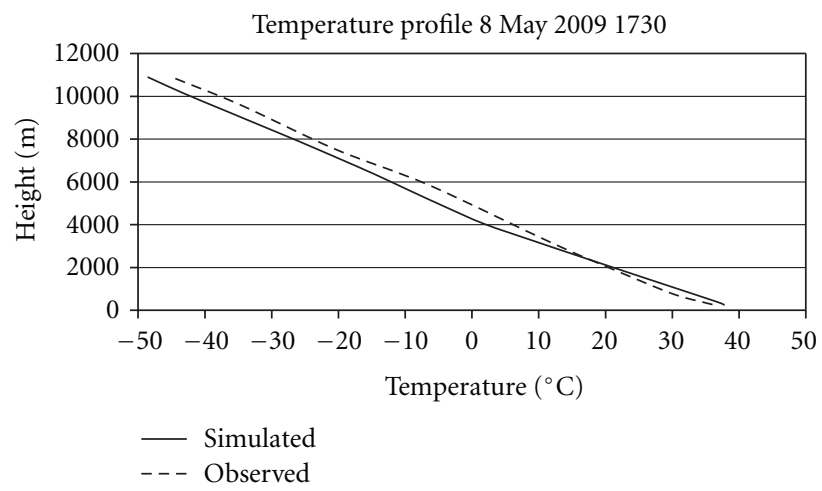

(d)

FIGURE 7: Temperature profile of selected days: 1 May 2009 and 8 May 2009 at 05301730 IST.

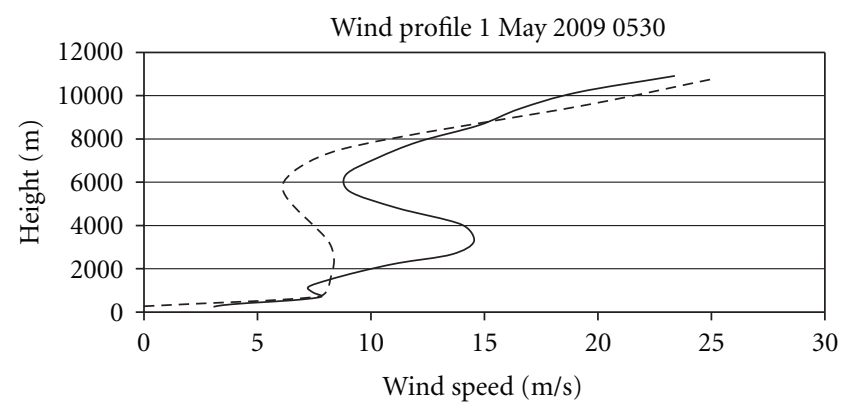

(a)

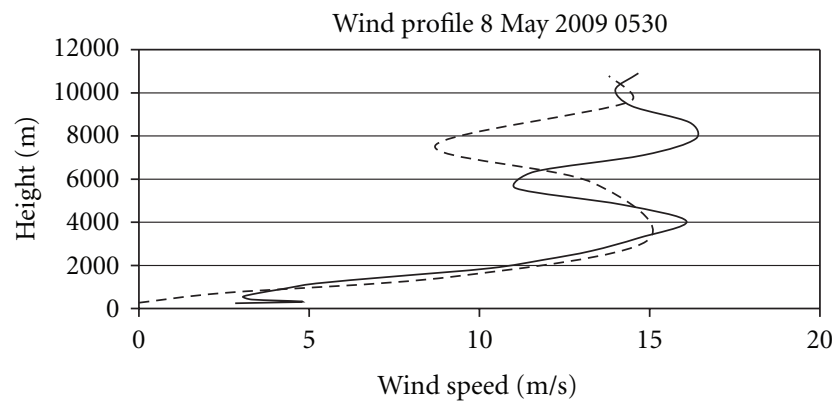

- - Simulated

(c)

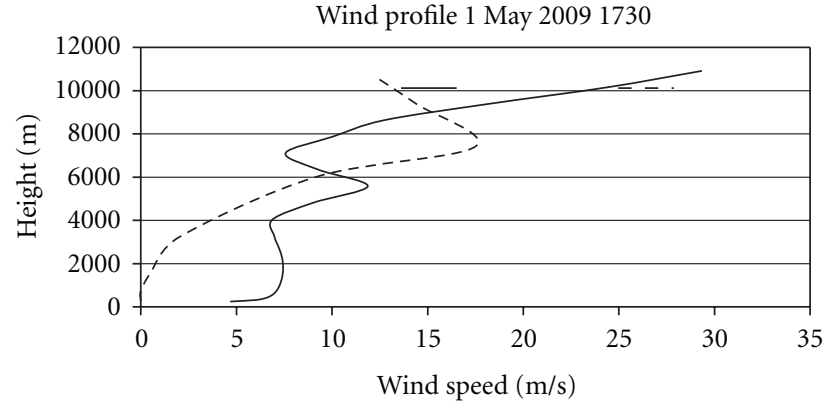

(b)

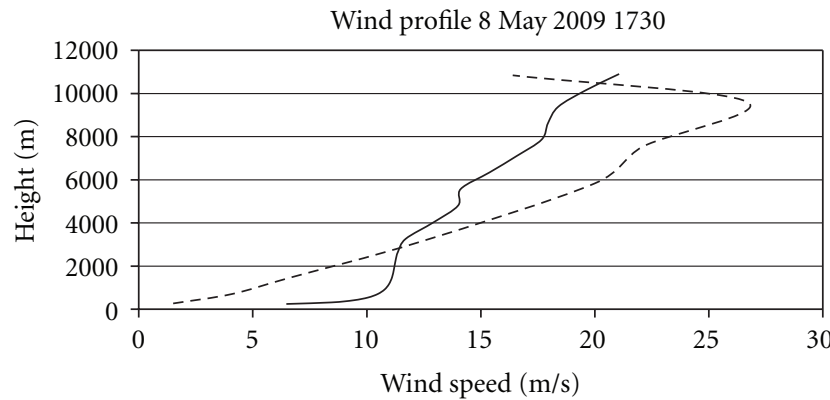

- Simulated

- - - Observed

(d)

FIgURE 8: Wind profile of selected days: 1 May 2009 and 8 May 2009 at 05301730 IST. 
TABLE 1: Simulations options used in the study.

\begin{tabular}{|c|c|c|c|c|c|c|}
\hline Simulation & Microphysics & Surface layer & Land surface & $\begin{array}{c}\text { Planetary } \\
\text { boundary layer }\end{array}$ & $\begin{array}{c}\text { Cumulus } \\
\text { parameterization }\end{array}$ & Experimental category \\
\hline 1 & Lin & Eta & Noah & MYJ & Kain-Fritsch & Default case \\
\hline 2 & Lin & QNSE & Noah & MYJ & Kain-Fritsch & $\begin{array}{l}\text { Experiment with surface } \\
\text { layer }\end{array}$ \\
\hline 3 & Lin & Eta & RUC (6) & MYJ & Kain-Fritsch & Experiment with LSM \\
\hline 4 & Lin & MM5 & Noah & YSU & Kain-Fritsch & $\begin{array}{l}\text { Experiment with surface } \\
\text { layer/PBL }\end{array}$ \\
\hline 5 & Lin & Eta & Noah & QNSE & Kain-Fritsch & Experiment with PBL \\
\hline 6 & Eta & Eta & Noah & MYJ & Kain-Fritsch & $\begin{array}{l}\text { Experiment with } \\
\text { microphysics }\end{array}$ \\
\hline 7 & Lin & Pleim & Pleim & ACM2 & Kain-Fritsch & $\begin{array}{l}\text { Experiment with surface } \\
\text { layer/LSM/PBL }\end{array}$ \\
\hline 8 & WSM 6 & Eta & Noah & MYJ & Kain-Fritsch & $\begin{array}{l}\text { Experiment with } \\
\text { microphysics }\end{array}$ \\
\hline 9 & Lin & Eta & Noah & MYJ & Grell-3d & $\begin{array}{l}\text { Experiment with cumulus } \\
\text { parameterization }\end{array}$ \\
\hline
\end{tabular}

TABLE 2: Statistical evaluation of summer simulations, station 1 .

\begin{tabular}{|c|c|c|c|c|c|c|c|c|c|}
\hline \multicolumn{10}{|c|}{ Temperature } \\
\hline & Sim_1 & Sim_2 & Sim_3 & Sim_4 & Sim_5 & Sim_6 & $\operatorname{Sim}_{-} 7$ & Sim_8 & Sim_9 \\
\hline RMSE (0) & 2.56 & 2.64 & 2.96 & 3.29 & 2.54 & 2.87 & 2.55 & 2.59 & 2.66 \\
\hline $\mathrm{FB}(0)$ & -0.04 & -0.02 & -0.02 & -0.08 & -0.03 & -0.04 & 0.02 & -0.04 & -0.04 \\
\hline$r(1)$ & 0.88 & 0.90 & 0.90 & 0.90 & 0.91 & 0.90 & 0.91 & 0.90 & 0.90 \\
\hline $\mathrm{FAC}_{2}(1)$ & 1.00 & 1.00 & 1.00 & 1.00 & 1.00 & 1.00 & 1.00 & 1.00 & 1.00 \\
\hline \multicolumn{10}{|c|}{ Wind speed } \\
\hline & Sim_1 & $\operatorname{Sim} \_2$ & Sim_3 & Sim $\_4$ & Sim_5 & Sim_6 & Sim_7 & Sim $\_8$ & Sim_9 \\
\hline RMSE (0) & 2.04 & 1.95 & 3.09 & 1.54 & 2.29 & 2.09 & 1.70 & 2.19 & 2.13 \\
\hline $\mathrm{FB}(0)$ & -0.41 & -0.31 & -0.64 & -0.14 & -0.43 & -0.40 & -0.33 & -0.42 & -0.43 \\
\hline$r(1)$ & 0.52 & 0.45 & 0.48 & 0.26 & 0.43 & 0.42 & 0.43 & 0.48 & 0.52 \\
\hline $\mathrm{FAC}_{2}(1)$ & 0.67 & 0.71 & 0.52 & 0.68 & 0.66 & 0.66 & 0.70 & 0.71 & 0.67 \\
\hline \multicolumn{10}{|c|}{ Relative humidity } \\
\hline & Sim_1 & Sim_2 & Sim_3 & Sim_4 & Sim_5 & Sim_6 & Sim_7 & Sim_8 & Sim_9 \\
\hline RMSE (0) & 14.57 & 13.32 & 14.85 & 20.03 & 14.07 & 14.85 & 11.55 & 14.78 & 13.35 \\
\hline $\mathrm{FB}(0)$ & 0.42 & 0.35 & 0.30 & 0.74 & 0.40 & 0.45 & 0.20 & 0.43 & 0.37 \\
\hline$r(1)$ & 0.74 & 0.74 & 0.69 & 0.77 & 0.75 & 0.76 & 0.79 & 0.72 & 0.79 \\
\hline $\mathrm{FAC}_{2}(1)$ & 0.79 & 0.87 & 0.71 & 0.37 & 0.81 & 0.75 & 0.89 & 0.79 & 0.85 \\
\hline
\end{tabular}

\subsection{Upper Air Variables}

5.3.1. Temperature and Wind Speed Profile in Boundary Layer. Figure 7 depicts height versus temperature in the boundary layer for two days of summer (simulation 7) at 0530 and 1730 hours (local time) of May 1 and May 8, 2009. Estimated profile is quite close to the observed profile for all the considered cases.

As explained in Section 5.2, wind speed is greatly influenced by local factors and thus not suitable for validation with point observation. However, to have a general idea of performance of the model for vertical profile of wind speed, profile was obtained from simulation 4 for two summer days (Figure 8). Deviations of simulated profile from the observed profile increase with increase in height.
This tendency has also been observed in some earlier studies $[2,36]$.

\section{Conclusions}

As discussed in the previous sections, there is no single combination of physics options that performs best for all the meteorological parameters. However, the present study suggests the suitable options for different meteorological variables under winter and summer conditions in a subtropical environment. Temperature and relative humidity are best estimated by coupled Pleim-Xiu ACM scheme while wind speed and direction are best simulated by MM5 surface layer LSM and YSU PBL schemes both for summer and winter seasons. Therefore, the model configuration should 
TABLE 3: Statistical evaluation of winter simulations, station 1.

\begin{tabular}{|c|c|c|c|c|c|c|c|c|c|}
\hline \multicolumn{10}{|c|}{ Temperature } \\
\hline & Sim_1 & Sim_2 & Sim_3 & Sim_4 & Sim_5 & Sim_6 & Sim_7 & Sim_8 & Sim_9 \\
\hline RMSE (0) & 3.78 & 3.34 & 4.24 & 4.25 & 3.57 & 3.85 & 2.96 & 3.73 & 3.75 \\
\hline $\mathrm{FB}(0)$ & -0.20 & -0.15 & -0.23 & -0.26 & -0.17 & -0.21 & -0.12 & -0.20 & -0.20 \\
\hline$r(1)$ & 0.83 & 0.84 & 0.81 & 0.85 & 0.83 & 0.83 & 0.86 & 0.83 & 0.83 \\
\hline $\mathrm{FAC}_{2}(1)$ & 0.98 & 0.99 & 0.99 & 0.99 & 0.99 & 0.98 & 1.00 & 0.98 & 0.98 \\
\hline \multicolumn{10}{|c|}{ Wind speed } \\
\hline & Sim_1 & Sim_2 & Sim_3 & Sim_4 & Sim_5 & Sim_6 & Sim_7 & Sim_8 & Sim_9 \\
\hline RMSE (0) & 1.12 & 0.88 & 1.18 & 0.76 & 1.21 & 1.13 & 1.08 & 1.08 & 1.12 \\
\hline $\mathrm{FB}(0)$ & -0.36 & -0.24 & -0.38 & -0.03 & -0.40 & -0.37 & -0.33 & -0.36 & -0.35 \\
\hline$r(1)$ & 0.74 & 0.75 & 0.73 & 0.74 & 0.72 & 0.77 & 0.67 & 0.76 & 0.72 \\
\hline $\mathrm{FAC}_{2}(1)$ & 0.78 & 0.84 & 0.73 & 0.74 & 0.75 & 0.79 & 0.65 & 0.79 & 0.77 \\
\hline \multicolumn{10}{|c|}{ Relative humidity } \\
\hline & Sim_1 & Sim_2 & Sim_3 & Sim_4 & Sim_ 5 & Sim_6 & $\operatorname{Sim}_{-} 7$ & Sim_8 & Sim_9 \\
\hline RMSE (0) & 37.65 & 34.33 & 46.87 & 48.37 & 34.91 & 38.00 & 24.01 & 37.23 & 37.60 \\
\hline $\mathrm{FB}(0)$ & 0.52 & 0.45 & 0.70 & 0.78 & 0.45 & 0.54 & 0.27 & 0.51 & 0.54 \\
\hline$r(1)$ & 0.58 & 0.61 & 0.48 & 0.62 & 0.60 & 0.64 & 0.77 & 0.58 & 0.67 \\
\hline $\mathrm{FAC}_{2}(1)$ & 0.73 & 0.80 & 0.34 & 0.28 & 0.77 & 0.71 & 0.93 & 0.75 & 0.71 \\
\hline
\end{tabular}

TABLE 4: Statistical evaluation of summer simulations, station 2.

\begin{tabular}{|c|c|c|c|c|c|c|c|c|c|}
\hline \multicolumn{10}{|c|}{ Temperature } \\
\hline & Sim_1 & $\operatorname{Sim} \_2$ & Sim_3 & Sim $\_4$ & Sim $\_5$ & Sim_6 & Sim_7 & Sim_8 & Sim_9 \\
\hline RMSE (0) & 3.23 & 2.60 & 3.58 & 4.26 & 3.19 & 3.61 & 2.48 & 3.23 & 3.23 \\
\hline $\mathrm{FB}(0)$ & -0.08 & -0.05 & -0.06 & -0.11 & -0.07 & -0.08 & -0.01 & -0.07 & -0.07 \\
\hline$r(1)$ & 0.92 & 0.94 & 0.87 & 0.91 & 0.92 & 0.90 & 0.94 & 0.91 & 0.92 \\
\hline $\mathrm{FAC}_{2}(1)$ & 1.00 & 1.00 & 1.00 & 1.00 & 1.00 & 1.00 & 1.00 & 1.00 & 1.00 \\
\hline \multicolumn{10}{|c|}{ Wind speed } \\
\hline & Sim_1 & Sim $\_2$ & Sim_3 & Sim $\_4$ & Sim $\_5$ & Sim_6 & $\mathrm{Sim}_{-} 7$ & Sim_8 & Sim_9 \\
\hline RMSE (0) & 2.50 & 2.23 & 3.28 & 1.69 & 2.61 & 2.49 & 2.10 & 2.39 & 2.46 \\
\hline $\mathrm{FB}(0)$ & -0.75 & -0.64 & -0.90 & -0.46 & -0.76 & -0.73 & -0.68 & -0.73 & -0.75 \\
\hline$r(1)$ & 0.43 & 0.43 & 0.43 & 0.19 & 0.40 & 0.41 & 0.45 & 0.49 & 0.48 \\
\hline $\mathrm{FAC}_{2}(1)$ & 0.38 & 0.48 & 0.29 & 0.53 & 0.37 & 0.34 & 0.37 & 0.42 & 0.39 \\
\hline \multicolumn{10}{|c|}{ Relative humidity } \\
\hline & Sim_1 & Sim_2 & Sim_3 & Sim_4 & Sim_5 & Sim_6 & Sim_7 & Sim_8 & Sim_9 \\
\hline RMSE (0) & 14.52 & 13.04 & 16.32 & 19.05 & 14.11 & 15.17 & 10.98 & 14.51 & 13.53 \\
\hline $\mathrm{FB}(0)$ & 0.35 & 0.28 & 0.22 & 0.67 & 0.34 & 0.38 & 0.15 & 0.36 & 0.31 \\
\hline$r(1)$ & 0.68 & 0.72 & 0.58 & 0.76 & 0.69 & 0.66 & 0.80 & 0.68 & 0.73 \\
\hline $\mathrm{FAC}_{2}(1)$ & 0.85 & 0.90 & 0.74 & 0.54 & 0.85 & 0.81 & 0.97 & 0.85 & 0.85 \\
\hline
\end{tabular}

be chosen from the viewpoint of the objective of the study undertaken. The best-performing options for temperature and relative humidity are likely to work better for fog-related studies while best performing options for wind velocity can perform better for dispersion studies. The main conclusions of this study are as follows.

(i) A case study for different physics options applicable in WRF (version 3.1.1) model for surface and upper air meteorological parameters for summer and winter seasons over subtropical region of Delhi has been performed. (ii) In general, the selection of surface layer, land surface model, and planetary boundary layer scheme was found to have more impact on output in comparison to microphysics and cumulus parameterization for both seasons.

(iii) Identification of model options for a given parameter and season is helpful for a particular model application. MM5-YSU combination works well for wind speed, and Pleim-ACM combination gives better temperature and moisture estimations. 
TABLE 5: Statistical evaluation of winter simulations, station 2.

\begin{tabular}{|c|c|c|c|c|c|c|c|c|c|}
\hline \multicolumn{10}{|c|}{ Temperature } \\
\hline & Sim_1 & Sim_2 & Sim_3 & Sim_4 & Sim_5 & Sim_6 & Sim_7 & Sim_8 & Sim_9 \\
\hline RMSE (0) & 4.20 & 3.63 & 4.51 & 4.68 & 4.07 & 4.25 & 3.14 & 4.17 & 4.13 \\
\hline $\mathrm{FB}(0)$ & -0.25 & -0.21 & -0.26 & -0.29 & -0.24 & -0.25 & -0.17 & -0.25 & -0.24 \\
\hline$r(1)$ & 0.84 & 0.86 & 0.79 & 0.85 & 0.84 & 0.84 & 0.88 & 0.83 & 0.84 \\
\hline $\mathrm{FAC}_{2}(1)$ & 0.99 & 1.00 & 0.99 & 0.97 & 0.99 & 0.99 & 1.00 & 0.99 & 0.99 \\
\hline \multicolumn{10}{|c|}{ Wind speed } \\
\hline & Sim_1 & Sim_2 & Sim_3 & Sim_4 & Sim_5 & Sim_6 & Sim_7 & Sim_8 & Sim_9 \\
\hline RMSE (0) & 1.51 & 1.30 & 1.69 & 1.02 & 1.56 & 1.60 & 1.59 & 1.55 & 1.53 \\
\hline $\mathrm{FB}(0)$ & -0.64 & -0.55 & -0.69 & -0.32 & -0.66 & -0.66 & -0.72 & -0.65 & -0.64 \\
\hline$r(1)$ & 0.75 & 0.74 & 0.72 & 0.66 & 0.74 & 0.72 & 0.63 & 0.73 & 0.74 \\
\hline $\mathrm{FAC}_{2}(1)$ & 0.51 & 0.58 & 0.42 & 0.52 & 0.49 & 0.49 & 0.26 & 0.49 & 0.49 \\
\hline \multicolumn{10}{|c|}{ Relative humidity } \\
\hline & Sim_1 & Sim_2 & Sim_3 & $\operatorname{Sim} \_4$ & Sim_5 & Sim_6 & Sim_7 & Sim_8 & Sim_9 \\
\hline RMSE (0) & 39.25 & 36.04 & 46.87 & 48.38 & 37.97 & 39.45 & 25.71 & 39.01 & 38.63 \\
\hline $\mathrm{FB}(0)$ & 0.57 & 0.51 & 0.73 & 0.81 & 0.54 & 0.59 & 0.33 & 0.56 & 0.57 \\
\hline$r(1)$ & 0.56 & 0.61 & 0.47 & 0.61 & 0.56 & 0.60 & 0.80 & 0.53 & 0.63 \\
\hline $\mathrm{FAC}_{2}(1)$ & 0.62 & 0.75 & 0.31 & 0.21 & 0.65 & 0.59 & 0.92 & 0.64 & 0.59 \\
\hline
\end{tabular}

(iv) Nested domains $(18,6$ and $2 \mathrm{~km})$ with higher resolutions were not helpful in improving the simulation results as per the current availability of the data.

(v) Overall, the present case study shows that the model performance is satisfactory over the subtropical region of Delhi.

\section{Acknowledgments}

The present study is a part of research project "Atmospheric Chemical Modelling in relation to Photochemical Smog over Delhi" funded by the Department of Science and Technology (DST), Government of India (DST No: SR/S4/AS : 249/05). The second author acknowledges Junior Research Fellowship support from DST.

\section{References}

[1] R. Borge, V. Alexandrov, J. José del Vas, J. Lumbreras, and E. Rodríguez, "A comprehensive sensitivity analysis of the WRF model for air quality applications over the Iberian Peninsula," Atmospheric Environment, vol. 42, no. 37, pp. 8560-8574, 2008.

[2] J. H. Kwun, Y. K. Kim, J. W. Seo, J. H. Jeong, and S. H. You, "Sensitivity of MM5 and WRF mesoscale model predictions of surface winds in a typhoon to planetary boundary layer parameterizations," Natural Hazards, vol. 51, no. 1, pp. 63-77, 2009.

[3] J. R. Krieger, J. Zhang, D. E. Atkinson, X. Zhang, and M. D. Shulski, "Sensitivity of WRF model forecasts to different physical parameterizations in the Beaufort sea region," in Proceedings of the 8th Conference on Coastal Atmospheric and Oceanic Prediction and Processes Phoenix, Ariz, USA, 2009.

[4] J. J. Ruiz, C. Saulo, and J. Nogués-Paegle, "WRF model sensitivity to choice of parameterization over South America: validation against surface variables," Monthly Weather Review, vol. 138, no. 8, pp. 3342-3355, 2010.

[5] J. Jin, N. L. Miller, and N. Schlegel, "Sensitivity study of four land surface schemes in the WRF model," Advances in Meteorology, vol. 2010, Article ID 167436, 11 pages, 2010.

[6] C. Misenis, X. Hu, S. Krishnan, and Y. Zhang, "Sensitivity of WRF/CHEM predictions to meteorological schemes," in Proceedings of the 14th Joint Conference on the Applications of Air Pollution Meteorology with the Air and Waste Management Association, Atlanta, Ga, USA, 2006.

[7] E. Flaounas, S. Bastin, and S. Janicot, "Regional climate modelling of the 2006 West African monsoon: sensitivity to convection and planetary boundary layer parameterisation using WRF," Climate Dynamics, pp. 1-23, 2010.

[8] M. Rajeevan, A. Kesarkar, S. B. Thampi, T. N. Rao, B. Radhakrishna, and M. Rajasekhar, "Sensitivity of WRF cloud microphysics to simulations of a severe thunderstorm event over Southeast India," Annales Geophysicae, vol. 28, no. 2, pp. 603-619, 2010.

[9] S. Pattanayak and U. C. Mohanty, "A comparative study on performance of MM5 and WRF models in simulation of tropical cyclones over Indian seas," Current Science, vol. 95, no. 7, pp. 923-936, 2008.

[10] S. K. Deb, T. P. Srivastava, and C. M. Kishtawal, "The WRF model performance for the simulation of heavy precipitating events over Ahmedabad during August 2006," Journal of Earth System Science, vol. 117, no. 5, pp. 589-602, 2008.

[11] A. Kumar, J. Dudhia, R. Rotunno, D. Niyogi, and U. C. Mohanty, "Analysis of the 26 July 2005 heavy rain event over Mumbai, India using the Weather Research and Forecasting (WRF)model," Quarterly Journal of the Royal Meteorological Society, vol. 134, no. 636, pp. 1897-1910, 2008.

[12] Y. V. Rama Rao, H. R. Hatwar, A. K. Salah, and Y. Sudhakar, "An experiment using the high resolution Eta and WRF models to forecast heavy precipitation over India," Pure and Applied Geophysics, vol. 164, no. 8-9, pp. 1593-1615, 2007.

[13] J. Dudhia, "WRF Modeling System Overview," 2010, http://www.mmm.ucar.edu/wrf/users/tutorial/201001/WRF _Overview_Dudhia.pdf. 
[14] National Centre for Atmospheric Research (NCAR), ARW Version 3 Modeling System's User's Guide, NCAR, Boulder, Colo, USA, 2010.

[15] National Centre for Atmospheric Research (NCAR), "A description of the advanced research WRF Version 3," NCAR Technical Note NCAR/TN-475+STR, NCAR, Boulder, Colo, USA, 2008.

[16] S. H. Chen and W. Y. Sun, "A one-dimensional time dependent cloud model," Journal of the Meteorological Society of Japan, vol. 80, no. 1, pp. 99-118, 2002.

[17] S. Y. Hong, J. O. J. Lim, and J. Dudhia, "The WRF singlemoment 6-class microphysics scheme (WSM6)," Journal of the Korean Meteorological Society, vol. 42, pp. 129-151, 2004.

[18] E. Rogers, T. Black, B. Ferrier, Y. Lin, D. Parrish, and G. Di Mego, "Changes to the NCEP Meso Eta Analysis and Forecast System: increase in resolution, new cloud microphyics, modified precipitation assimilation, modified 3DVAR analysis," NWS Technical Procedures Bulletin, 2001.

[19] J. S. Kain and J. Kain, "The Kain - Fritsch convective parameterization: an update," Journal of Applied Meteorology, vol. 43, no. 1, pp. 170-181, 2004.

[20] W. C. Skamarock, J. B. Klemp, J. Dudhia et al., "A description of the advanced research WRF version," Technical Note TN468+STR, NCAR, Boulder, Colo, USA, 2005.

[21] Z. I. Janjic, "Nonsingular Implementation of the MellorYamada Level 2.5 Scheme in the NCEP Mesomodel," NCEP Office Note 437, 2002.

[22] R. C. Gilliam and J. E. Pleim, "Performance assessment of new land surface and planetary boundary layer physics in the WRFARW," Journal of Applied Meteorology and Climatology, vol. 49, no. 4, pp. 760-774, 2010.

[23] S. Y. Hong, Y. Noh, and J. Dudhia, "A new vertical diffusion package with an explicit treatment of entrainment processes," Monthly Weather Review, vol. 134, no. 9, pp. 2318-2341, 2006.

[24] F. Chen and J. Dudhia, "Coupling and advanced land surfacehydrology model with the Penn State-NCAR MM5 modeling system-part I: model implementation and sensitivity," Monthly Weather Review, vol. 129, no. 4, pp. 569-585, 2001.

[25] M. B. Ek, K. E. Mitchell, Y. Lin et al., "Implementation of Noah land surface model advances in the National Centers for Environmental Prediction operational mesoscale Eta model," Journal of Geophysical Research D, vol. 108, no. 22, pp. 1-16, 2003.

[26] E. J. Mlawer, S. J. Taubman, P. D. Brown, M. J. Iacono, and S. A. Clough, "Radiative transfer for inhomogeneous atmospheres: RRTM, a validated correlated-k model for the longwave," Journal of Geophysical Research D, vol. 102, no. 14, pp. 663682, 1997.

[27] J. Dudhia, "Numerical study of convection observed during the Winter Monsoon Experiment using a mesoscale twodimensional model," Journal of the Atmospheric Sciences, vol. 46, no. 20, pp. 3077-3107, 1989.

[28] GIS Development Geospatial Resource Portal, "Earthquakes in Delhi," 2009, http://www.gisdevelopment.net/application/ natural_hazards/earthquakes/nheq0007.htm.

[29] Weather Underground, "About our Data," http://www.wunder ground.com/about/data.asp.

[30] WMO Guide to Meteorological Instruments and Methods of Observation, http://www.wmo.int/pages/prog/www/IMOP/ publications/CIMO-Guide/CIMO_Guide-7th_Edition-2008 .html.

[31] J. J. Cassano and M. E. Higgins, "Development of a regional arctic climate system model: performance of WRF for regional pan-Arctic atmospheric simulations," in Proceedings of the 11th WRF Users' Workshop National Center for Atmospheric Research, Boulder, Colo, USA, 2010.

[32] T. Prabha and G. Hoogenboom, "Evaluation of the Weather Research and Forecasting model for two frost events," Computers and Electronics in Agriculture, vol. 64, no. 2, pp. 234247, 2008.

[33] http://www.ncdc.noaa.gov/oa/climate/igra/.

[34] V. S. Challa, J. Indrcanti, J. M. Baham et al., "Sensitivity of atmospheric dispersion simulations by HYSPLIT to the meteorological predictions from a meso-scale model," Environmental Fluid Mechanics, vol. 8, no. 4, pp. 367-387, 2008.

[35] S. Mayer, A. Sandvik, M. O. Jonassen, and J. Reuder, "Atmospheric profiling with the UAS SUMO: a new perspective for the evaluation of fine-scale atmospheric models," Meteorology and Atmospheric Physics, 2010.

[36] S. R. Hanna, B. Reen, E. Hendrick et al., "Comparison of observed, MM5 and WRF-NMM model-simulated, and HPAC-assumed boundary-layer meteorological variables for 3 days during the IHOP field experiment," Boundary-Layer Meteorology, vol. 134, no. 2, pp. 285-306, 2010.

[37] S. Das, R. Ashrit, G. R. Iyengar et al., "Skills of different mesoscale models over Indian region during monsoon season: forecast errors," Journal of Earth System Science, vol. 117, no. 5, pp. 603-620, 2008.

[38] J. W. Nielsen-Gammon, X.-M. Hu, F. Zhang, and J. E. Pleim, "Evaluation of planetary boundary layer scheme sensitivities for the purpose of parameter estimation," Monthly Weather Review, vol. 138, no. 9, pp. 3400-3417, 2010.

[39] X.-M. Hu, J. W. Nielsen-Gammon, and F. Zhang, "Evaluation of three planetary boundary layer schemes in the WRF model," Journal of Applied Meteorology and Climatology, vol. 49, no. 9, pp. 1831-1844, 2010. 

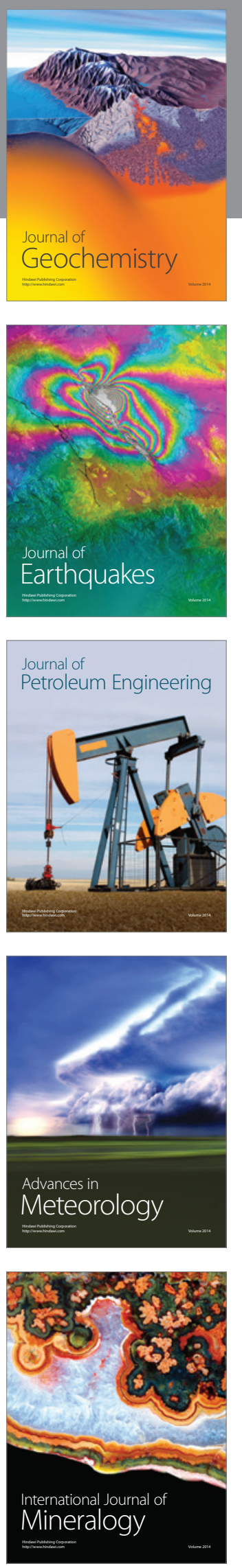
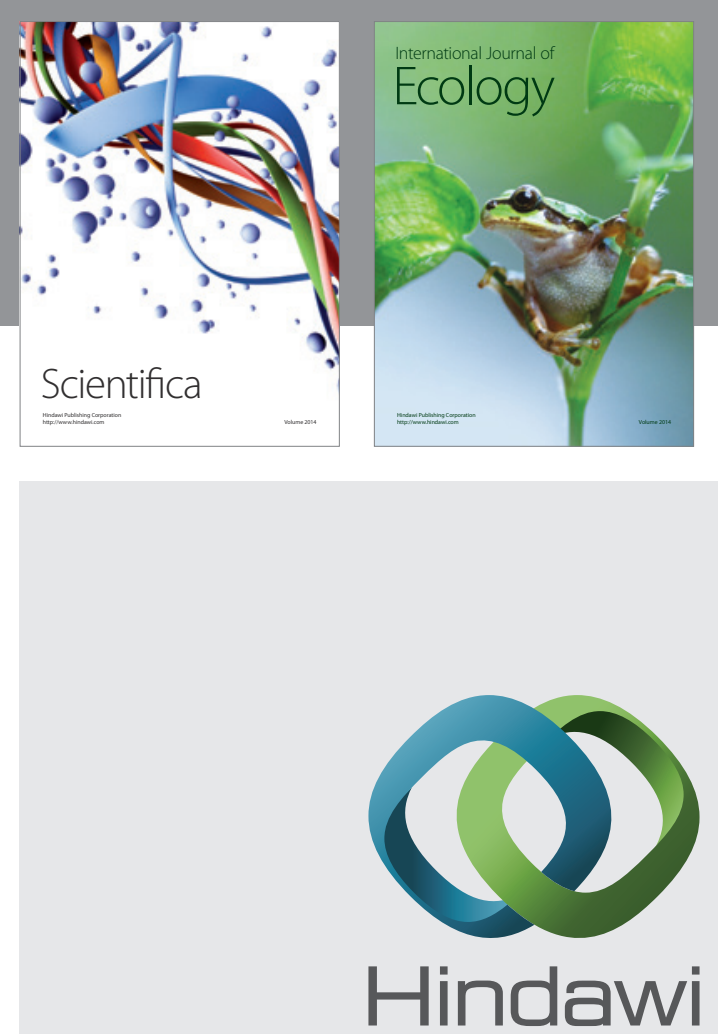

Submit your manuscripts at http://www.hindawi.com
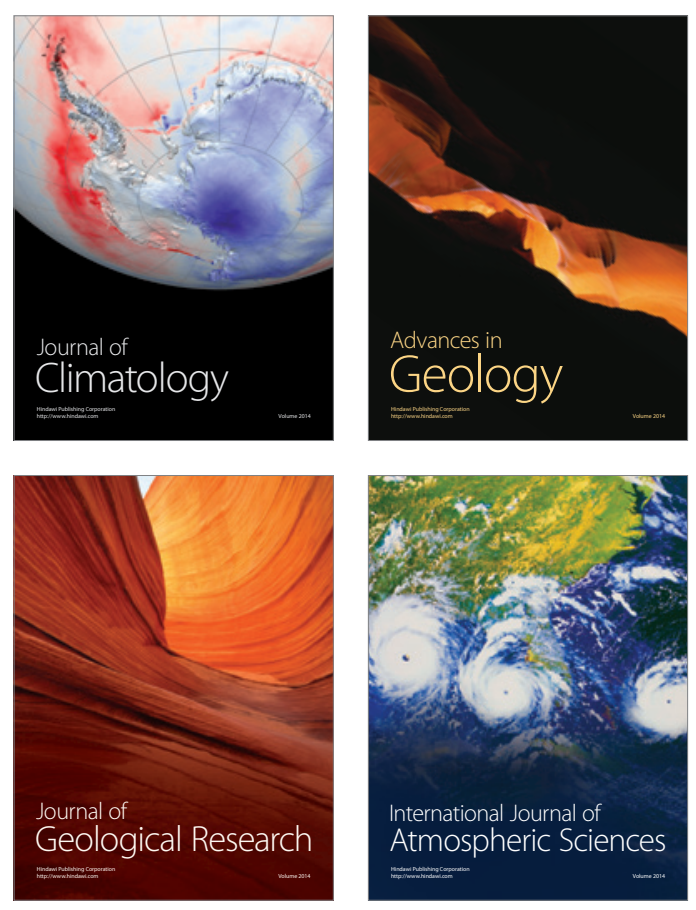
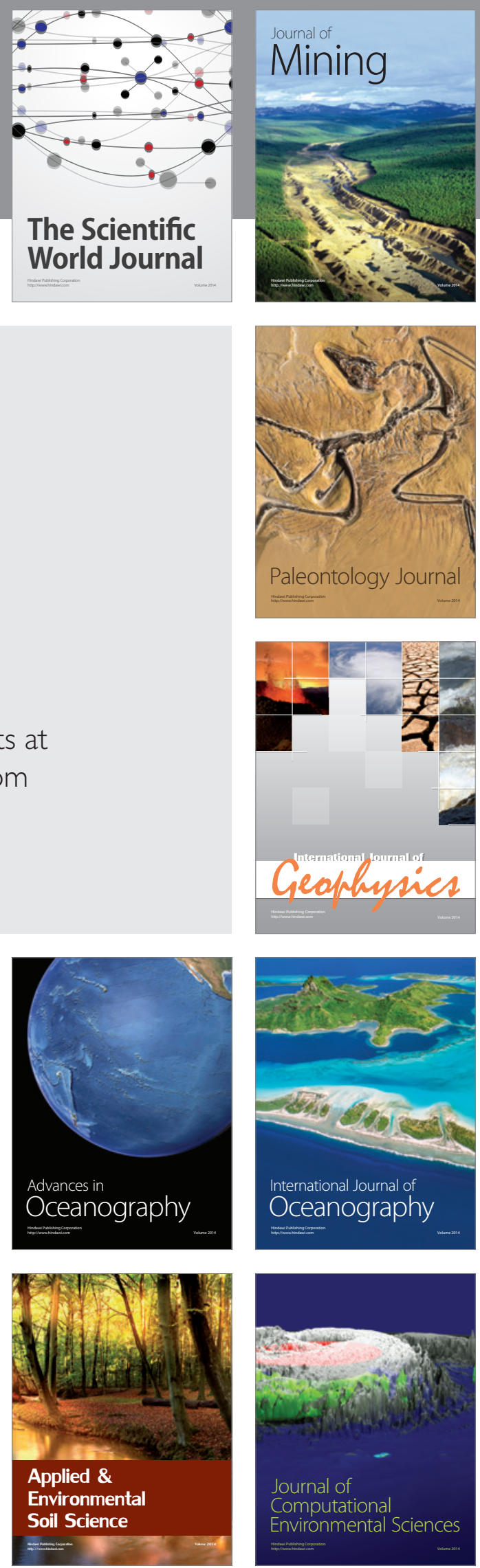